\title{
CONF-790803--36
}

\section{FUSION-SUPPORTED DECENTRALIZED NUCLEAR ENERGY SYSTEM}

D. L. JASSBY

Plasma Physics Laboratory, Princeton University

Princeton, NJ 08544

April 1979

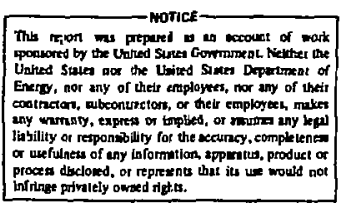

Paper to be presented at the 14th Intersociety Energy

Conversion Engineering Conference, Boston, Mass., August 5-10, 1979. 


\title{
FUSION-SUPPORTED DECENTRALIZED NUCLEAR ENERGY SYSTEM
}

\author{
D. L. JASSBY \\ Plasma Physics Laboratory, Princeton University \\ Princeton, NJ 08544
}

\begin{abstract}
A decentralized nuclear energy system is proposed comprising mass-produced pressurized water reactors in the size range 10 to $300 \mathrm{MW}$ (thermal), to be used for the production of process heat, space heat, and electricity in applications where petroleum and natural gas are presently used. Special attention is given to naximizing the refueling interval with no interim batch shuffling in order to minimize fuel transport, reactor downtime, and opfortunity for fissile diversion. The smallest reactors could be deployed as "nuclear batteries," kept in the equivalent of spent-fuel shipping casks and returned to nuclear fuel centers for refueling.

These objectives demand a substantial fissile enrichment (7 to 15\%). The preferred fissile fuel is $U-233$, which offers an order of magnitude savings in ore requirements (compared with $\mathrm{U}-235$ fuel), and whose higher conversion ratio in thermal reactors serves to extend the period of useful reactivity and relieve demand on the fissile breeding plants (compared with $\mathrm{Pu}-239$ fuel). Application of the neutral-beam-driven tokamak fusion-neutron source to a U-233 breeding pilot plant is examined.

This scheme can be extended in part to a decentralized fusion energy system, wherein remotely located large fusion reactors supply excess tritium to a distributed system of relatively small nonbreeding $D-T$ reactors.
\end{abstract}




\section{MOTIVATION}

There is a growing need for alternative energy systems to reduce petroleum consumption in satisfying local requirements for both heat and electricity. In the U.S., about $35 \%$ of petroleum usage is for space heating and industrial heating. In view of potential safety problems in operating fission reactors, it would appear that power reactors should be located in remote areas perhaps liundreds of kilometers from the load. However, remote deployment woukl preclude direct use of the heat generated by the power plants. Placement of reactors within $30 \mathrm{~km}$ of the load center can more readily be justified in the case of much higher efficiency of end use - up to $70 \%$ in the case of co-generation (both heat and electricity), and up to $85 \%$ for heat production alone. The effective efficiency is also enhanced by the smaller losses in short distribution systerns.

The present paper proposes a rec.ctor deployment plan [I] that takes advantage of the fact that fission reactors can be constructed in arbitrarily small size and with lengthy intervals between refueling (as in naval reactors), and that thermal converter reactors operate best with U-233 fuel. The ability to prolong the refueling period with enriched reactor fuel can make possible a type of "nuclear battery," which is desirable both from the standpoint of increased availability and for minimizing the transport of nuclear fuels. While close-in reactors generally should be located underground, the smallest versions proposed herein could be kept in the equivalent of spent-fuel shipping casks.

The principal arguments for preferring smaller power units are the following:

- Srnall units have more flexible siting, because they require less cooling wiater and land.

- Siting near the point of application results in large savings in transmission lines, substations, and lost power, and encourages co-generation. 
1 Small stondardized units can be prefabricated and delivered on a relatively short time scale, resulting in large savings in "interest during construction" and cost escalation.

- Because large numbers of small units can be made for a given power capacity, only a very small fraction - the lead units - will face serious operational problems that require "debugging."

An assured supply of $\mathrm{U}-233$ or Pu-239 is needed to eliminate the problems arising fromi an eventual shortage of uranium ore. The required long-term availability of U-233 or Pu-239 can be obtained by breeding in thorium or depleted uranium blankets surrounding $D-T$ or D-D fusion-neutron sources $[2,3]$. The most practical fusion-neutron source for the near term appears to be a neutral-beamdriven tokamak plasma. Beam-injected tokamak plasmas have already generated neutron intensities of $10^{14} \mathrm{n} / \mathrm{s}$ in deuterium operation, which is equivalent to about $10^{16} \mathrm{n} / \mathrm{s}$ in D-T operation, at $Q_{p} \approx 0.02$ [4]. There seems little doubt that in larger machines using the higher energy, more powerful neutral-beam injectors currently under development, 14-MeV neutron intensities of $10^{20} \mathrm{n} / \mathrm{s}(250 \mathrm{MW})$ with fusion energy multiplication of at least 1 to 2 will in fact be attained.

This scheme can be extended in part to a decentralized fusion energy system, wherein remotely located large fusion reactors supply excess tritium to a distributed system of relatively small nonbreeding $D-T$ reactors [5]. The large reduction in tritium inventory and other safety benefits that accrue from elimination oî tritium breeding enhance the attractiveness of close-in siting. 


\section{THE DECENTRALIZED NUCLEAR ENERGY SYSTEM}

\subsection{General Description}

The present approach is based on the mass production of a few types of standard, small, sealed units fueled preferably by U-233. This distributed nuclear system would complement the system of large electrical power plants maintained by the electric utilities.

The proposed system has the following principal features:

- The fission reactors are thermal converters available only in four unit sizes of $10,30,100$, or $300 \mathrm{MW}$ (thermal).

- Each unit is of standardized design, mass-produced off-site.

- The reactors are used to supply process heat or space heat, and electricity in some applications (i.e., co-generation).

- The reactors are fueled by U-233, produced by fusion-driven breeders located in a smiall number of safeguarded nuclear fuel centers.

- The reactors are refueled only at lengthy intervals, up to 6 years. The smallest inits can be operated as "nuclear batteries," and returned to the fuel centers for refueling.

Fission reactors can in fact be manufactured in arbitrarily small size, and small reactors, particularly pressurized light-water reactors, have satisfied mobile and remote-site power needs: in the propulsion of surface ships and submarines [6], and as power spurces for remote military installations [7], and for space vehicle power systems [8]. The largest reactor size proposed in the present plan (300 MWt) is comparable in size with the Babcock and Wilcox Co. Consolidated Nuclear Steam Generator (CNSG), first designed for ship propulsion and later proposed for industrial applications [9].

The flexibility in the siting of smal! plants encourages diverse co-generation applications (both steam or high temperature gas and electricity usage). 
Applications would include process heat for large factories, chemical plants, and smelters; district heat and electricity for small cities, for large self-contained commercial centers, and for industrial enterprises and habitats on the seabed; semi-portable electrical power sources for large construction sites and mines, such as might now be served by diesel generators or gas turbines; propulsion systems for large ships. The use of small fission reactors for peak-load power generation could also be considered.

\subsection{Market Size}

The potential market size for this distributed reactor system is indicated by the volume of present usage of petroleum in the United States for industrial heating of all types and for space heating, namely, about 7 million bpd (barrels per day). One million bpd is equivalent to $67 \mathrm{GW}(\mathrm{t})$. Hence if the small reactor's are to capture $20 \%$ of the present petroleum heating market over a period of 20 years, then an annual incremental deployment of $5.9 \mathrm{GW}(\mathrm{t})$ is required, assuming operation at $80 \%$ capacity factor. Considering that this market is likely to expand, and that naturai gas usage for similar purposes may eventually have to be Curtailed, one can envisage an annual market in the U.S.A. for small reactors of $10 \mathrm{GW}(\mathrm{t})$. If the average plant size is, for exampie, $67 \mathrm{MW}(\mathrm{t})$, then the number of reactors ordered annually would be 150. These orders might be distributed as fifteen $300 \mathrm{MW}(\mathrm{t})$ units, thirty-five $100 \mathrm{MW}(\mathrm{t})$ units, fifty $30 \mathrm{NW}(\mathrm{t})$ units, and fifty $10 \mathrm{MW}(\mathrm{t})$ units. These quantities are sufficiently large to permit the use of mass production techniques by several manufacturers sharing the market.

\subsection{Characteristics of the Srnall Reactors}

A wide variety of reactor types have been made in small sizes, although it seems likely that PWRs (pressurized water reactors) would be the favored type for some time. The high power density characteristic of PWRs using moderately 
enriched fuel is especially valuable for the smaller mobile units. Safety problems associated with small reactors are expected to be less severe than with large reactors [10], because all the components of the former can be installed in a single reactor pressure vessel, as in the CNSG [9], and no large connecting pipes are needed between components. However, advanced gas-cooled reactors may eventually be preferred because of their ability to provide higher temperature heat, and because of considerable safety advantages over PWRs.

Table 1 gives representative dimensions of the containment vessels of PWRs in the size range 10 to $300 \mathrm{MW}(\mathrm{t})$. The 10 and $30 \mathrm{MW}(\mathrm{t})$ units would be completely factory assembled, then delivered to the operating site. With continuous production lines, delivery and installation could be made v'ithin 24 months of placement of order. These smaller units would be shipped and maintained in the equivalent of spent-fuel shipping casks [11], impervious to radioactive releases.

The 100 and $300 \mathrm{MW}(\mathrm{t})$ units would require underground site preparation (uriess barge mounting were employed), but with the exception of the containment building, the components would be factory manufactured and delivered to the site in a few shipments. 


\section{FUELING INTERVAL AND THE NUCLEAR BATTERY}

\subsection{Refueling Strategy}

The present plan proposes a lengthy refueling interval (6 years) in order to minimize fuel transport, reactor downtime, and the opportunity for fissile diversion. This period is sufficiently long so that the relatively mobile 10 and $30 \mathrm{MW}(\mathrm{t})$ units could be returned to nuclear fuel centers for refueling. Thus the fuel assemblies would be securely sealed before delivery, and there would be no onsite fueling or batch shuffling whatever, the reactor units being treated like "disposable batteries." The smallest reactors would be housed in the equivalent of spent-fuel shipping casks [11], and operated on motorized or barge-mounted platforms. While the $100 \mathrm{MW}$ and $300 \mathrm{MW}(\mathrm{t})$ units would normally be located underground, the nuclear battery concept would be practical even with these sizes if the reactors were barge-mounted.

The objectives of extended refueling interval and minimum reactor size demand a substantial fissile enrichment. A prototypical decentralized nuclear energy system along the above lines already exists in the form of navai reactor deployment [6]. Naval reactors have been designed for refueling intervals of more than 10 years with no interim batch shuffling. Such extended refueling intervals are made possible with highly enriched cores, and with an extreme dependence on the control rods and burnable poisons to soak up excess reactivity during the first years of operation on a new fuel charge. However, such operation is extremely wasteful of the available neutron supply. The present scheme considers moderately enriched fuel, up to $15 \%$ (a fissile concentration still too small for use in explosives).

Figure $1(a)$ shows the fuel burn-up during residence in a PWR as a function of U-235 enrichment, $Y$. In the multi-batch fuel management schemes, at some 
regular interval the 3 or 4 batches in the core are shuffled, and one batch is replaced by fresh fuel so that the reactor output remains reasonably constant. This interval is 12 to 18 months in present commercial practice. Reference [12] gives examples of such burn-up data for the multibatch scheme. In the 60-month onebatch scheme indicated in Fig. I(a), there is no fuel shuffling and all fuel assemblies are replaced after 75 months assuming operation at $80 \%$ capacity factor. It is at this frequency - once every 6 years - that a 10 or $30 \mathrm{MW}(\mathrm{t})$ nuclear battery would be returned to the nuclear fuel center for reloading.

To maintain the power output reasonably constant for 6 years, considerable use would have to be made of soluble poisons in the coolant and burnable poisons strategically distributed among the fuel pins, as well as programmed withdrawal of the control rods. Nevertheless, with $\mathrm{U}-235$ fuel the maximum output power will begin to decline after about 4 years, falling to about $70 \%$ of its initial value after 60 equivalent full-power months of operation. In the case of U-233 fuel, the power reduction is smaller, because of the higher conversion ratio of $\mathrm{U}-233$ in thermal reactors [13]. (Conversion ratio $=$ fraction of fissile atom bred per fissile atom burned.)

The high reactivity that is characteristic of a completely new fuel load could also be reduced by the proposed spectral shift control technique in which the anitial moderator would be $80 \% \mathrm{D}_{2} \mathrm{O}$, to be replaced gradually by $\mathrm{H}_{2} \mathrm{O}$ during the lifetime of the fuel [14]. This procedure leads to a flatter power output with time, with the unwanted neutrons utilized for fissile (or tritium) breeding rather than wasted. However, on-site operations would be more complicated.

Figure $I(b)$ shows the "apparent fuel utilization," defined as $(Y-1.4) / Y$, where it is assumed that the fuel can always be burned down to a fissile content of 1.4 weight percent. In practice the gain in fuel utilization at large $Y$ will be poorer than indicated for extended period operation because of the build-up of unwanted 
neutron absorbers, but this loss is partly compensated by the build-up and burning of $\mathrm{Pu}-239$ in uranium-fueled reactors.

The rapid increase in fuel burn-up [Fig. I(a)] with enrichment is due to three factors: (i) increased fissile enrichment; (ii) increased fuel utilization [Fig. I(b)]; and (iii) the build-up and burning of Pu-239. The latter effect is very small for the 12-month multi-batch scheme, but becomes important for extended operation. As can be deducet from Fig. 1(a), the burn-up per unit fissile feed actually decreases with increasing refueling period, because of the increased loss of neutrons to unwanted neutron poisons as well as the loss in the first years of operation to burnable poisons installed to reduce high reactivity.

The fuel cladding must be designed for burn-ups of 100,000 MWD/MT, a value that is already feasible with HTGR fuel [15]. (The fuel residence time in an HTGR with $Y=6.5 \%$ can be as long as 6 years, but batch shuffling and $1 / 6$ fuel replacement are required annually [15].)

\subsection{Ore Requirement}

If uranium fuel with U-235 enrichment $Y(w t .9)$ is produced in an isotope separation plant leaving tails having a wt. $\% \mathrm{~T}$, it is easy to show that $\mathrm{W}$, the number of tons of uranium ore $(0.71 \% \mathrm{U}-235)$ required to produce one ton of reactor fuel is

$$
W \approx \frac{Y-T}{0.71-T}
$$

Figure 1 shows $W$ versus fissile enrichment $Y, T=0.2 \%$ is about the bes, that can be achieved in diffusion or centrifuge separation plants, while laser separation techniques should give $T<0.1 \%$. For one ton of fuel enriched to $5 \%$ or more, eight tons or more of uranium ore must be mined, compared with only one ton of thorium with the same enrichment of U-233 bred in a fusion-driven breeder. From the point of view of ore maning, $\mathrm{Pu}-239$ breeding is even more favorable because it would make use of the enormous stores of depleted uranium. The above statements 
hold for once-through cycles. If reprocessing and further enrichment is carried out, the ore penalty for using $U-235$ is even greater. Note that the reduction in ore requirement is accompanied by a corresponding reduction in radioactive mill tailings which must be disposed of.

\subsection{Summary of the Advantages of U-233}

The preferred fissile fuel for the decentralized nuclear energy system is U-233, or secondarily Pu-239, for the following reasons:

(i) Savings in Ore Resources. Economically recoverable supplies of U-235 are limited. As discussed in Section 3.2, the breeding of U-233 from thorium or Pu-239 from depleted uranium offers an order of magnitude reduction in ore requirement for a once-through cycle.

(ii) Extended Power Characteristics. The higher conversion ratio of $U-\hat{z} 33$ in thermal reactors extends the period of useful reactivity beyond that obtainable with either U-235 or Pu-239 at the same initial enrichment. Hence with U-233 there is less decrease in the power output toward the end of the proposed 6 year operating period.

(iii) Reduced Fusion Breeder Capacity. The higher conversion ratio offered by $U-233$ results in more fissile fuel recovered per cycle through the fission burner, if reprocessing is performed. Hence a fusion breeder of a given fissile production rate can fuel a larger number of converters burning U-233 rather than $\mathrm{Pu}-239[2,3]$. 


\section{THE FUEL CENTERS}

The breeding of U-233 (or Pu-239) and its fabrication into fuel rods would be carried out at a number of safeguarded "fuel centers" closely regulated by the federal government. In addition to one or more fusion-driven breeders (FDB), each center would comprise a nuclear fuel fabrication plant, a reprotessing plant, a waste disposal facility, and facilities for decommissioning the smaller reactor units which are returned here at end-of-life. All spent fuel rods would be returned to the fuel centers for reprocessing to concentrate the unburned U-233, or for storage.

\subsection{Fuel-Producing Blanket}

The performance of the many possible FDB blankets have been treated in detail elsewhere $[2,3]$. In order to generate at least one fissile atom per fusion neutron (an arbitrary goal), and at the same time breed tritium to sustain the fusion driver, it is advisable to maximize the neutron population by $(n, x n)$ and fastfission reactions with the $14 \mathrm{MeV}$ fusion neutrons. It seems likely that the front end of the blanket will consist of a thin depleted-uranium layer for neutron and power multiplication, in which the plutonium concentration will be allowed to build up to at least $3 \%$ and power multiplication $M$ as large as 10 will be obtained. Neutrons produced in the multiplier will leak into the remainder of the blanket comprising thorium and lithium layers, thereby producing U-233 for sale and adequate tritium to sustain the fusion driver.

The optimal thermal output of the FDB is that which provides just enough electricity to drive the fusion neutron source, as well as satisfy the power requirements of other facilities located at the same site. If (fusion power/plant input electrical power) $=0.5$, and energy conversion efficiency $=0.35$, then $M=6$ allows the FDB power needs to be satisfied. Excess electrical power generated by the FDB can be used to produce portable chemical fuels such as hydrogen. 


\subsection{Number of Fuel Producing Reactors}

The capacity of a fusion breeder can be ineasured by its fusion power production, $P_{F}$, its annual net production of fissile material, and its total thermal power production, $\mathrm{P}_{\text {FDB }}$. The FDB capacity required to fuel a system of fission reactors with totai thermal output $P_{R}$ depends on their conversion ratio, $C$, the performance of the FDB blanket, and the degiee of reprocessing of the spent fuel. Many recent studies $[2,3]$ have determined the "support ratio" $P_{R} / P_{F D B}$ for a system of fission reactors of given conversion ratio, $C$. The result is that a fusion breeder can supply adequate fuel to sustain 3 to 20 times its own thermal capacity of fusion reactors, although the larger ratios imply the use of advanced converters such as the HTGR and full reprocessing of spent fuel. The condition $P_{R} / P_{F D B}=5$ can be met for fueling PWRs operating on the thorium cycle $[16]$, where $C=0.75$. Taking $P_{R} / P_{F D B}=5$, a $2000 \mathrm{MW}(\mathrm{t}) \quad \mathrm{FDB}$ is required to supply our postulated annual incremental deployment of $10,000 \mathrm{MW}(\mathrm{t})$ of fission reactors, assuming the same capacity factors. This size is thought to be convenient for a single moderately large FDB, with $P_{F} \approx 450 \mathrm{MW}$ and $M \sim 5$. Thus a single FDB could provide make-up fuel for 150 small fission reactor: with the postulated average size of $67 M W(t)$.

For a system of $\mathrm{C}=0.75$ fission reactors of total power $300 \mathrm{GW}$ (thermal), only 30 FDBs of $2000 \mathrm{MW}(t)$ size would be required, and this number could be reduced if thermal reactors with $\mathrm{C}>0.75$ were deployed and full reprocessing carried out. Thus several thousand small reactors would eventually be supplied fuel by perhaps 10 fuel centers. This centralization of fuel supply for a decentralized power system is no different in principle from a few dozen oil refineries providing oll for a hundred thousand outlets, or a few dozen factories manufacturing components for a million solar energy conversion sites. 


\section{DEVELOPMENT REQUIREMENTS FOR \\ THE FUSION-DRIVEN BREEDER}

\subsection{Characteristics of the Fusion Pilot Plant}

Many analyses of FDB (fusion-driven breeder) systems have shown that fusion energy multiplication $Q_{p} \gtrsim 1$ and fusion driver electrical energy gain $Q_{E} \geq 0.5$ are required for approximate economic viability, in addition to other restrictions on the capital cost of the plant per unit fusion power capacity [2-3]. As discussed in detail in Ref. [17] and indicated in Fig. 3, the beam-driven tokamak system is by far the best candidate for achieving $Q_{p} \sim 1$ in quasi-steady operation, with $Q_{E} \sim 0.5$ also achievable with the introduction of superconducting coils and improved neutral-beam injector efficiency.

Table 2 compares the parameters of a postulated FDB pilot plant with those of several neutral-beam-driven tokamak systems existing or under construction. A pilot plant is not expected to demonstrate economic viability or even high availability, but it should demonstrate high-duty-factor operation with $Q_{p} \sim 1$. The most attractive mode of reactor-plasma operation is one that is intermediate between the "energetic-ion" and TCT regimes [18]. Here the beams provide all fueling, maintain the bulk-plasma temperaiure, and in principle can drive the plasma current, so that steady-state operation might be feasible. The central region of the beam-injected PLT plasma is located in this transition regime, under conditions where the neutron production rate is maximum. To sustain this operating mode, plasma recycling must be minimized by an unload magnetic divertor, or by a magnetic limiter coupled to a large-area getter pumping system.

Present large tokamak plasmas already operate with $<n_{\mathrm{e}}>{ }^{T} \mathrm{E}$ up to $5 \times 10^{12} \mathrm{~cm}^{-3}$, but $T_{e}(0)$ and $\bar{E}_{i o n}$ are about a factor of 4 smaller than required for an FDB pilot plant. Beam-injection experiments indicate that if impurity levels 
can be controlled, then $T_{e}$ can be raised with higher injection powers, while $\bar{E}_{\text {ion }}$ will be increased as the neutral-beam energy is raised above the presentday value of $40 \mathrm{keV}$. Injection of both $\mathrm{D}$ and $\mathrm{T}$ beams may be required to maintain the plasma composition during steady-state or quasi-steady operation [18].

There is no question of the "scientific feasibility" of the FDB plasma. But as suggested in Table 2, enormous advances must be made in tokamak plasma and machine engineering to attain high-duty-factor operation with acceptable overall energy balance, and with sufficiently large neutron wall loading.

\subsection{Summary of Development Requirements}

The tokamak fusion neutron source of a fissite-breeding pilot plant must have the following characteristics (see Table 2):

- 14-MeV neutron intensity $\gtrsim 3 \times 10^{19} \mathrm{n} / \mathrm{s}$, and neutron wall loading $\gtrsim 0.4 \mathrm{MW} / \mathrm{m}^{2}$.

- $Q_{p} \gtrsim 1$, implying that $\left\langle T_{e}>\gtrsim 5 \mathrm{keV}\right.$.

- Neutral-beam injector efficiency $\eta_{I} \geq 0.4$.

- Quasi-steady operation.

The following are the minimal developinent requirements needed to upgrade present beam-injected tokamak devices:

- Superconducting toroidal-field coils with the ability to operate in the pulsed-field tokamak environment. Normal coils could be used with the penalty of increased power dissipation, which might be acceptable at large blanket $M$.

- Means of steady-state heat removal from the plasma, the first wall, and in-torus particle collection systems.

$\because$ Steady-state impurity control.

- Efficient neutral-beam injectors with $E_{b}=100$ to $150 \mathrm{keV}\left(D^{\circ}\right)$, which requires the introduction of direct energy recovery techniques. 


\section{4}

- Optimal remute maintenance and assembly procedures to minimize downtime of a large activated tokamak.

An economically viable FDB, as distinst from a pilot plant, would require a larger neutron intensity and wall loading than the values given above, and the product $\eta_{I} Q_{p}$ may have to be at least 1 . 


\section{EXTENSION TO A DISTRIBUTED D-T REACTOR SYSTEM}

The concept discussed herein can be extended in part to the deployment of a system of relatively small D-T tokamak power reactors which do not breed tritium, but which are fueled by shipments from large tritium-breeding reactor:s (D-T or D-D) sited at the nuclear fuel centers [5]. While such "satellite" fusion systems have been proposed for $D-{ }^{3} \mathrm{He}$ reactors [19], the more demandinis plasma requirements of $D^{3}{ }^{3}$ He reactors make them an unlikely prospect in the torseeable future. It is important to observe that to obtain an environmentally benign and easily maintainable tokamak fusion reactor, there is no need to reduce neutron intensities to the levels characteristic of $\mathrm{D}^{3}{ }^{3} \mathrm{He}$ reactors - räther it is tritium breeding that needs to be eliminated.

Nonbreeding $\mathrm{D}-\mathrm{T}$ reactors are as environmentally benign as $\mathrm{D}-\mathrm{D}$ reactors, and almost as favorable as $\mathrm{D}-{ }^{3}$ He reactors. They have the advantage over both $D-D$ and $D-{ }^{3}$ He systems of being much cheaper $(\$ / k W)$, and realizable in the relatively near future.

\subsection{Advantages of the Distributed System}

The advantages of the system proposed herein over "conventional" D-T reactor siting are the following (see Table 3):

(i) Environmental. The absence of tritium breeding allows a reduction of at Jeast a factor of 25 in the reactor tritium inventory, and also eliminates the lithium fire hazard. Most important, elimination of the need to carefully utilize the blanket neutrons permits the optimal choice of blanket materials for minimizing neutron activation [20]. [A disadvantage is that tritium fuel shipments have to be relatively frequent, perhaps quarterly, because of the short decay time of tritium ( $5 \%$ loss per year). About $90 \%$ of the on-site triitum would be stored in a vault isolated from the reactor, so that it would not be involved in an accident to the reactor.] 
(ii) Capital Cost. The absence of a breeding blanket enables smaller and less complicated D-T reactors, with power production as low as $700 \mathrm{MW}$ (thermal). Hence unit capital cost requirements should be much reduced.

(iii) Higher Plant Availability. Downtime for maintenance and repairs would be reduced because of the choice of minimum-activity blankets as swell as the absence of tritium in the blankets.

(iv) Sitling. The smaller and safer nonbreeding plants would allow more flexible siting, which is conducive to co-generation applications. Transmission costs are reduced.

\subsection{Support Ratio}

The tritium breeders in the fuel centers are analogous to the fissile fuel breeders in the decentralized fission reactor system (see Section 4). A D-T fusion reactor with a beryllium multiplier in the blanket can exhibit a tritium breeding ratio of up to 1.9 [19]. Allowing $5 \%$ loss of tritium in processing and storage, the support ratio (= number of nonbreeding $\mathrm{D}-\mathrm{T}$ reactors supported by one breeding D-T reactor of the same fusion capacity) is only 0.8 , and only about 0.6 if evaluated with respect to total thermal output of the reactors $(M \approx 1.6$ for the breeder and 1.2 for the burner). However, the widely deployed nonbreeding reactors would be used for co-generation or for heat production alone, giving a useful efficiency up to $85 \%$. In effect, the support ratio would then be as large as $0.6 \times(0.35 / 0.35)=1.5$

Because the breeders would be made much larger than the distributed reactors in order to take advantage of the economies of scale, it is likely that a breeder can support a system of nonbreeding plants whose capital cost is also of the order of 1.5 times that of the breeder. The entire system would clearly not be economic, however, unless the electrical power of the breeder itself were utilized. 
Public concern may in fact demand that tritium-breeding fusion reactors be relatively isolated, so that the distributed system of nc.ibreeding co-generation reactors would be a useful adjunct. As an example, a $7000 \mathrm{MW}(\mathrm{t})$ breeder could deliver $2000 \mathrm{MW}(\mathrm{e})$ by long-distance transmission line, and also fuel 6 nonbremding D-T reactors each furnishing $600 \mathrm{MW}$ of useful heat to nearby locations.

Eventually it might be feasible to use very large "catalyzed-deuterium" reactors for the breeder. Because half the fusion neutrons would be 2.5 MeV below neutron multiplying thresholds - the tritium breeding ratio would be only about 1.4, but the maximum energy support ratio of small heat-producing $D-T$ burning reactors could be effectively as large as 2.5 .

In any event, DT-burning tokamak power reactors that are free of tritium breeding appear to be technologically feasible, and may be the safest and most environmentally benign concentrated power source of any type.

\section{ACKNOWLEDGMENT}

Useful comments on an early version of this papt: [1] were provided by S. L. Bogart, C. S. Caldwell, J. A. Maniscalco, and C. E. Singer. This work was supported by the U.S. Department of Energy, Office of Fusion Energy, under Contract No. EY-76-C-02-3073. 


\section{REFERENCES}

1. D. L. Jassby, Princeton Plasma Physics Laboratory Report PPPL-TM-316 (June 1978), unpublished.

2. C. Taylor (Editor), Proc. US-USSR Symposium on Fusion-Fission Reactors (Lawrence Livermore Lab, 1976), CONF-760733.

3. S. L. Bogart (Editor), Proc. Second MFE Fusion-Fission Energy Systems Review Meeting (Washington, D. C., 1977), CONF-771155.

4. P. L. Colestock, et al., "Neutron Producìion During Deuterium Neutral-Beam Injection into the PLT Tokamak," Princeton Plasma Physics Laboratory Report (to be published).

5. D. L. Jassby, Proc. 16th Annual Symposium Idaho Section of the American Society of Mechanical Engineers (Idaho Falls, 1979) pp. 88-90.

6. N. Polmar, Atomic Sulmarines (Van Nostrand, Princeton, 1963); Nuclear Ship Propulsion (IAEA, Vienna, 1961).

7. C. H. Fox, New Scientist, No. 264 (7 Dec 1961) p. 611.

8. J. E. Brunings, et al., Nucl. Tech. 22 (1974) p. 237.

9. Babcock and Wilcox Company, "A Small Pressurized Water Reactor for Process Energy," Report BAW-1428 (1976).

10. R. C. Sanders, G. E. Mueller, Nucl. Tech. $\underline{42}$ (1979) p. 289.

11. U. S. Department of Energy, "Transportation of High-Level Nuclear Wastes," Report ERDA-8 (1974).

12. N. L. Shapiro, Y. Liu, Trans. Am. Nucl. Soc. 30 (1978) p. 276.

13. APS Study Group on Nuclear Fuel Cycles and Waste Management, Rev. Mod. Phys. 50 (1978).

14. D. Mars, et al., "Spectral Shift Control Reactor Design and Economic Study," Babcock and Wilcox Company Report BAW-1241 (1961). 
15. P. R. Kasten, et al., "Assessment of the Thorium Fuel Cycle in Power Reactors," Oak Ridge National Laboratory Repurt ORNL/TM-5565 (1977).

16. R. P. Rose, et al., "Preliminary Conceptual Design of a Demonstration Tokamak Hybrid Reactor," Westinghouse Electric Corp. Report WFPS-TME-086 (1978).

17. D. L. Jassby, "Maximum Neutron Yields in Experimental Fusion Devices," Princeton Plasma Physics Laboratory Report PPPL-1515 (1979).

18. D. L. Jassby, Nucl. Fusion $\underline{17}$ (1977) p. 309.

19. G. M. Miley, et al., Proc. EPRI Review Meeting on Advanced-Fuel Fusion, Chicago, IIl., 1977), EPRI Report ER-536-SR, Pp. 39-56.

20. J. Fillo, J. Powell, ibid., Pp. 57-68.

21. D. C. Quimby, G. L. Woodruff, Trans. Am. Nucl. Soc. 29 (1978) p. 38. 


\section{Table 1}

CHARACTERISTICS OF SMALL PRESSURIZED WATER REACTORS ${ }^{*}$

$\begin{array}{lcccc}\text { Thermal Output (MW) } & 10 & 30 & 100 & 300 \\ \begin{array}{l}\text { Equivalent Oil Consumption (bpd) } \\ \text { Annual Value of Oil Replaced, }\end{array} & 150 & 450 & 1500 & 4500 \\ \begin{array}{l}\text { Assuming 80\% Capacity Factor } \\ \text { and Oil at \$20/Barrel (\$ million) }\end{array} & 0.88 & 2.6 & 8.8 & 26 \\ \text { Reactor Vessel O.D. (m) } & 2.0 & 2.7 & 3.5 & 4.5 \\ \text { Containment Vessel O.D. (m) } & 10 & 12 & 14 & 15 \\ \text { Containment Vessel Height (m) } & 11 & 14 & 17 & 20 \\ \text { Core Coolamt Flow (kg/s) } & 400 & 650 & 2200 & 3000\end{array}$

${ }^{*}$ Extrapolated from Refs. [9] and [7]. 
Table 2

PARAMETERS OF EXPERIMENTAL NEUTRAL-BEAM-DRIVEN TOKAMAKS AND A FUSION BREEDER PILOT PLANT

\begin{tabular}{|c|c|c|c|c|}
\hline & $\begin{array}{l}\text { PLT } \\
(1978)\end{array}$ & $\begin{array}{c}\text { PDX } \\
(1980)\end{array}$ & $\begin{array}{l}\text { TFTR } \\
(1983)\end{array}$ & $\begin{array}{l}\text { Fusion Breeder } \\
\text { pilot Plant (1990) }\end{array}$ \\
\hline Major radius (m) & 1.4 & 1.4 & 2.5 & 4.5 \\
\hline Plasma current (MA) & 0.2 & 0.6 & 2.5 & 3.0 \\
\hline Beam energy (keV) & 39 & 50 & 120 & $\begin{array}{l}100 \mathrm{keV}\left(\mathrm{D}^{\circ}\right) \\
150 \mathrm{keV}\left(\mathrm{T}^{\circ}\right)\end{array}$ \\
\hline Beam power ( $M W$ ) & 2.4 & 6.0 & 25 & $\begin{array}{l}50 \mathrm{MW}\left(\mathrm{D}^{\mathrm{o}}\right) \\
50 \mathrm{MW}\left(\mathrm{T}^{\mathrm{o}}\right)\end{array}$ \\
\hline$<n_{e}>\tau_{e}\left(\mathrm{~cm}^{-3} \mathrm{~s}\right)$ & $1 \times 10^{12}$ & $3 \times 10^{12}$ & $1.5 \times 10^{13}$ & $3 \times 10^{13}$ \\
\hline $\mathrm{T}_{\mathrm{e}}(0)(\mathrm{keV})$ & 4.0 & 5.0 & 10 & 12 \\
\hline $\bar{E}_{\text {ion }}(0)(k e V)$ & 12 & 25 & 35 & 60 \\
\hline Neutrons/s (D-D) & $1 \times 10^{14}$ & $3 \times 10^{15}$ & $5 \times 10^{16}$ & - \\
\hline Neutrons/s (D-T equiv.)* & $\sim 1 \times 10^{16}$ & $\sim 3 \times 10^{17}$ & $\sim 1 \times 10^{19}$ & $7 \times 10^{19}$ \\
\hline $\begin{array}{l}\text { Neutron Wall Loading* } \\
\left(\mathrm{MW} / \mathrm{m}^{2}\right) \text { (D-T equiv.)* }\end{array}$ & $\sim 0.001$ & $\sim 0.02$. & $\sim 0.15$ & 0.5 \\
\hline$Q_{p}(D-T$ equiv.)* & 0.02 & 0.2 & 1.0 & 2 \\
\hline Pulse length (s) & 0.15 & 0.5 & 1.5 & $250 \mathrm{~s}$ \\
\hline Duty factor & 0.001 & 0.003 & 0.005 & 20.8 \\
\hline
\end{tabular}

* For PLT and PDX, which use only deuterium fuel, the equivalent values for D-T fuel are given. 
Table 3

BREEDING AND NONBREEDING TOKAMAK D-T KEACTORS

\section{BREEDING NONBREEDING}

Reactor Tritium Inventory

Lithium Inveritory

Relative Degree of Activation

Minimum Thermal Power

Major Radius of Plasma

$$
210 \mathrm{~kg}
$$

200 tons

1

$1800 \mathrm{MW}$

$\sim 6 \mathrm{~m}$
$0.4 \mathrm{~kg} *$

0

$0.01 *$

$700 \mathrm{MW}$

$\sim 5 \mathrm{~m}$

* Corresponding to 4 days burn-up in the smallest possible reactor $(700 \mathrm{MWt})$. An additional $10 \mathrm{~kg}$ is stored in a vault isolated from the reactor.

**With optimal choice of blanket materials. 

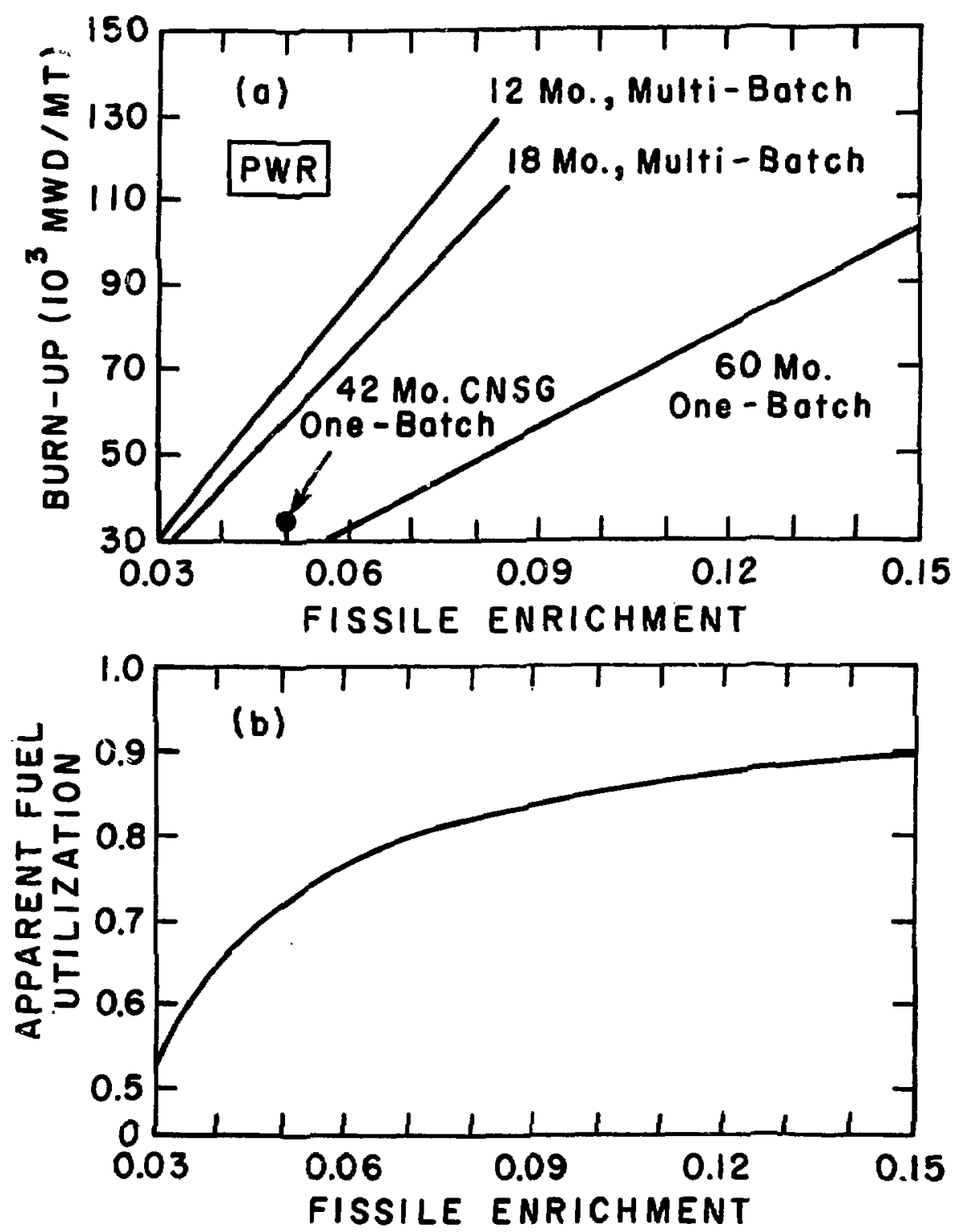

793490

Fig. 1. (a) Maximum fuel burn-up in FWR's with various fuel management schemes, as a function of fissile enrichment of fresh fuel batches. (b) Maximum utilization of iritial fuel loading, assuming burn-up to $1.4 \%$ fissile. 


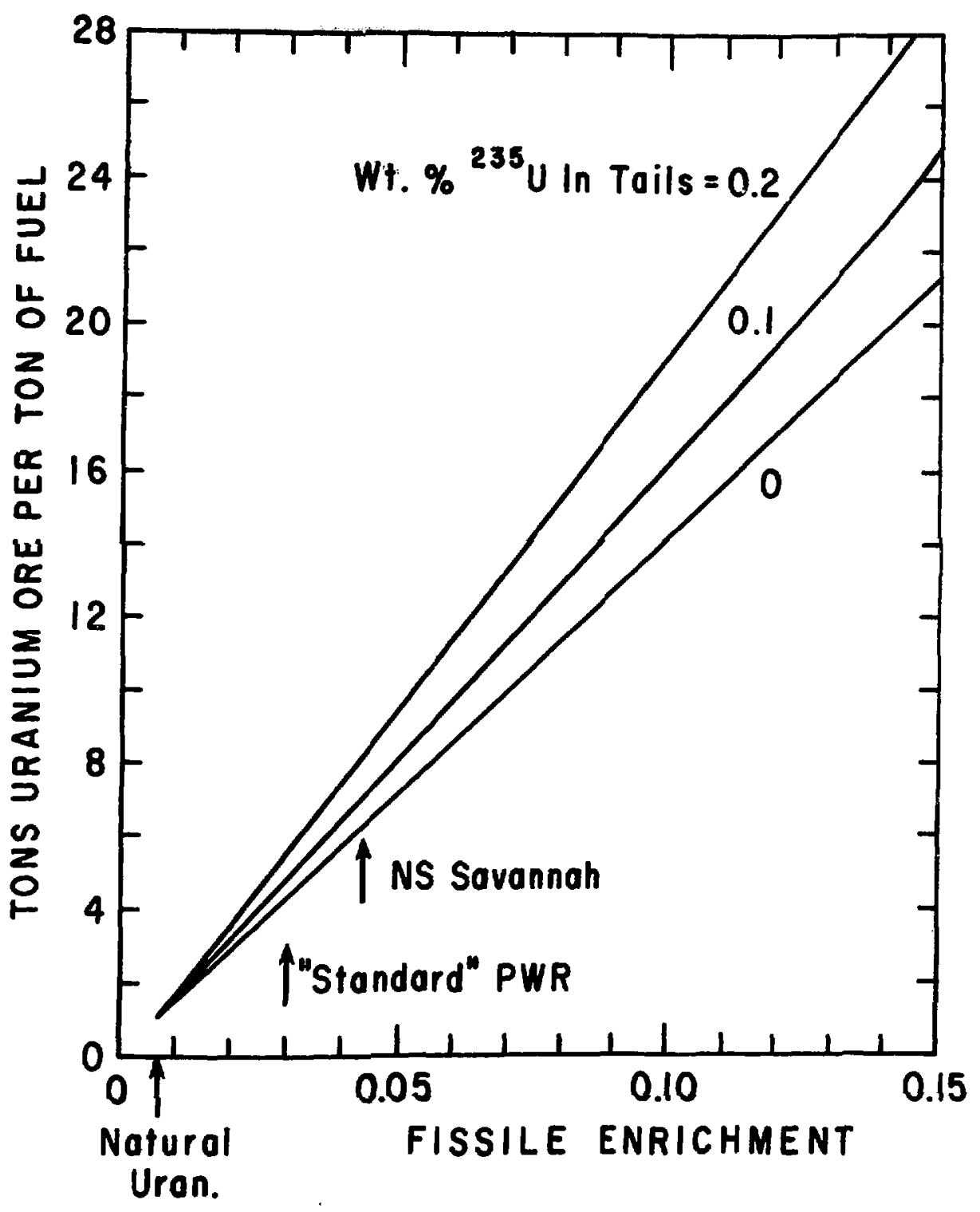

793510

Fig. 2. Weight of uranium ore required to supply one ton of reactor fuel, as a function of U-235 fissile enrichment. 


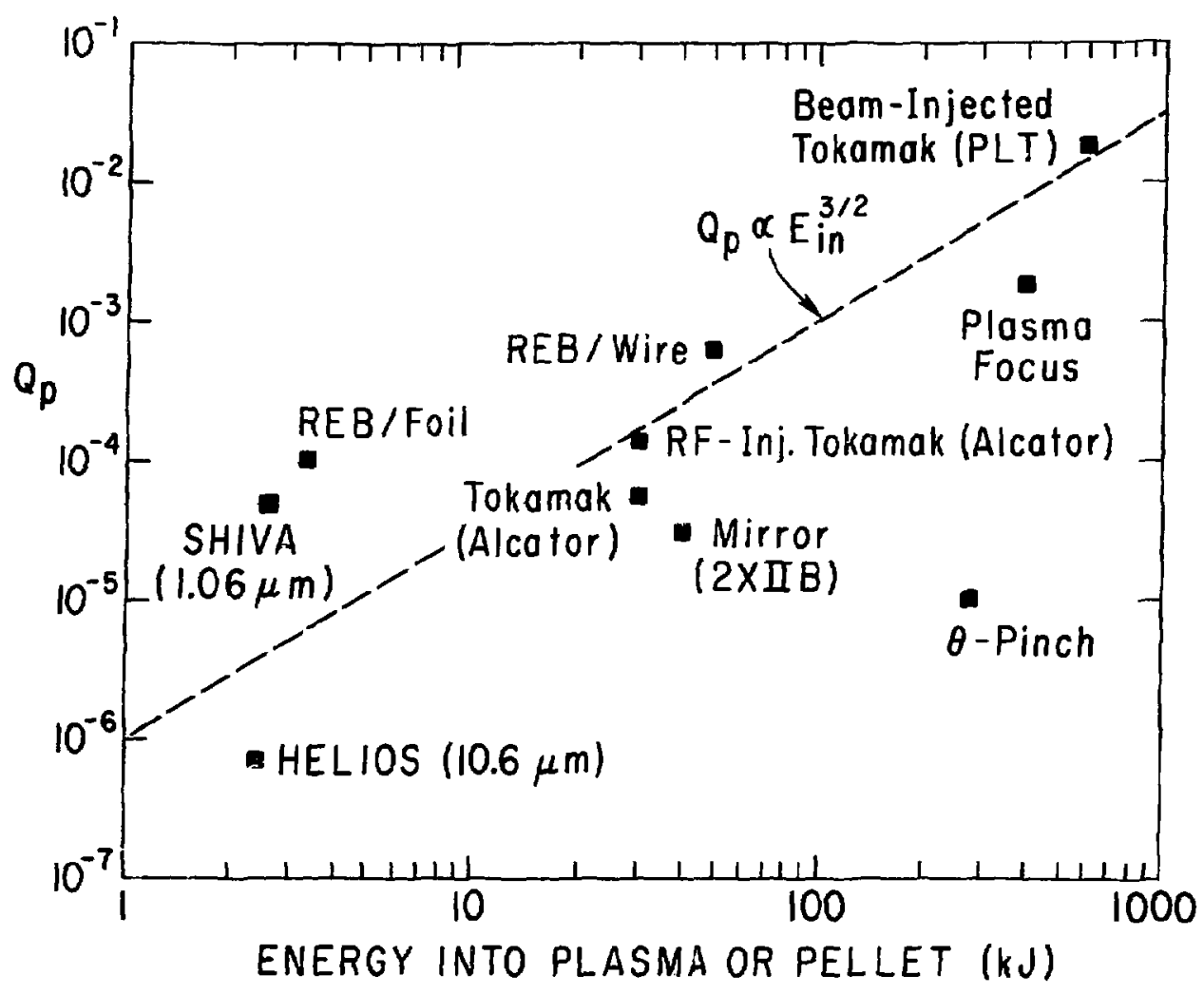

793206

Fig. 3. Record values of fusion power multiplication or fusion energy multiplication $Q_{p}$ versus energy injected into the plasma (tokamak or mirror devides) or delivered to the pellet, foil, wire, or electrodes. For systems that have used only deuterium, the equivalent $Q_{p}$ for $D-T$ fuel is given. 


\section{ALL CATECIORIES}

12. Askew, Auburn University, Alabama

5. T. Wu, Univ. of Alabama

Geophysical Institute, Univ. of Alaska

6.L. Johnston, Sonoma State Univ, California

H. H. Kuehl,Univ. of S. California

Institute for Energy Studies, Stanford University

H. D. Campbell, University of Florida

N. L. Oleson, University of South Florida

W. M. Stacey, Georgia Institute of Technology

Benjamin Ma, lowa State University

Hagne Kristiansen, Texas Tech, University

W. L. Wiese, Nat'l Bureau of Standards, Wash., D.C.

Australian National University, Canberra

C.N. Watson-Munro, Univ, of Sydney, Australia

i. Cap, Inst. for Theo. Physics, Austria

Ecole Royale Militaire, iruxelles, Belgium

1). Palumbo, C. Europear Comm. B-1049-Brussels

P.H. Sakanaka, Instituto de Fisica, Campinas, Brazil

C. R. Janies, University of Alberta, Canada

T.W. Johnston, INRS-Energie, Vareenes, Quebec

H. M. Skarsgard, Univ. of Saskatchewan, Canada

Librarian, Culhain Laboratory, Abingdon, England

A.M. Dupas Library, C.E.N.-G, Grenoble, France

Central Res. Inst. for Physics, Hungary

R. Shingal, Mecrut College, India

A.K. Sundaram, Phys. Res. Lab., India

V. Naraghi, Atomic Energy Org. of Iran

Biblioteca, Frascati, Italy

Biblioteca, Milano, It aly

G. Rostagni, Univ. Di Padova, Padova, Italy

l'reprint Library, Inst. de Fisica, Pisa, Italy

Library, Plasma Physjcs Lab., Gokasho, Uji, Japan

\$. Mori, Japun Atomic Energy Res. Inst.,Tokai-Mura

Research Inior mation Center, Nagoya Univ., Japan

S. Shioda, Trukyo Inst. of Tech.,Japan

Inst. of Space \& Aero. Sci., Univ, of Tokyo

T. Uchida, Univ. of Tokyo, Japan

H. Yamato, Toshiba R. \& D. Center, Japan

M. Yoshikawa, JAERI, Tokai Res. Es' ,, Japan

N. Yajima, Kyushu Univ., Japan

R. England, Univ. Nacional Auto-noma de Miexico

13. S. Liley, Iniv. of Waikato, New Zealand

S. A. Moss, Saab Univas Nor ge, Norway

J.A.C. Cabral, Univ, de Lisbaa, Portugal

O. Petrus, AL.I. CUZA Univ., Romania

1. de Villiers, Atomic Energy Bd., South Africa

A. Haurech, Comisaria De La Energy y Recoursos Minerales, Spain

Library, Royal Institute of Technology, Sweden

Cen. de Res. En Phys.Des Plasmas, Switzerland

Librarian, Fom-Instituut Voor Plasma-Fysica, The Netherlands

V. E. Golant, A.F. lofle Physical-Tech. Inst.,USSR

B.B. Kadomisev, Kurchatov Inst. of Atomic Energy, USSR

The Kharkov Physical-Tech. Inst., USSR

M. S. Rabinovich, Academy of Sci, USSR tribliothek, Stuttgart, itest cicrinumy

R.I). Buhler, Univ. of Seut tg.ant, West Germany

Max-Planck-Inst. fur Plasmaphysik, W. Germany

Nucl. Res. Estab., Julich, West Cermany

K. Schindler, Inst. Fur Theo. Physik, W. Germany

\section{EXPERIMENTAL \\ THEORETICAL}

iv. H. Brennan, FJinders Univ. Austrajia

H. Barnard, Univ. of British Columbia, Canada

S. Screenivasan, Univ. of Calgary, Canada

3. Radet, C.E.N.-B.P., Fontenay-aux-Roses, France

Prof. Schatzman, Observatoire de Nice, France

S. C. Sharma, Univ. of Cape Coast, Ghand

R. N. Aiyer, Laser Section, India

B. Buti, Physical Res. Lab., India

L. K. Chavda, S. Gujarat Univ., India

I.M. Las Das, Banaras Hindu Univ., India

5. Cuperrnan, Tel Aviv Univ., Israel

E. Greenspan, Nuc. Res. Center, Isracl

P. Rosenau, Israel Inst. of Tech., Israel

int'. Center for Theo. Physics, Trieste, Italy

I. Kawakami, Nihon Universjty, Japan

(2) T. Nakayama, Ritsumeikan Unjv., Japan

S. Nagao, Tohoku Univ., Japan

J.1. Sakai, Toyama Uirv., Japan

S. Tjotta, Univ. I Bergen, Norway

M.A. Hellberg, Univ. of Natal, South Africa

H. Wilhelmson, Chalutuers Univ. of Tectı., Sweden

Astro. Inst., Sonnenborgh Obs., The Netherlands

N.G. Tsintsadze, Academy of Sci GSSK, USSR

T. 3. Boyd, Univ. College of North Wales

K. Hubner, Univ. Heidelberg, W.Germany

H. J. Kaeppeler, Univ. of Stut tgart, West Germany

K. H. Spatschek, IJniv. Essen, West Cermany

\section{EXPERIMENTAL \\ ENLINEERING}

13. Grek, Univ. du Quebec, Canuda

P. Lukac, Komenskcho Univ., Czechosluvalkia

G. Horikoshi, Nat'l Lab lor High Erergy Physics, Tsukuba-Gun, Japan

V. A. Glukhikh, D.V. Efremov Sci. Res. Instit.of Elect. App., (ISSR

\section{EXPERINIENTAL}

F. J. Paoloni, Univ. of Wollongong, Australia

3. Kistemaker, Fom Inst. iur Atornic \& iMolec. Physics, The Netherlands

\section{THEORETICAL}

F. Verheest, tnst. Vor Theo. Mach., Belgium

3. Teichrnann, Univ. of Nontreal, Canada

T. Kahan, Univ. Paris VII, France

R. K. Chhailani, India

S. K.. Trehan, Panjab Univ., India

T. Namikawa, Osaka City Uniy., Japan

H. Narumi, Univ. of Hiroshima, Japan

Korea Atornic Energy Res. Inst., Korea

E. T. Karlson, Uppsala Univ., Sweden

L. Stenflo, Univ. of UMEA, Swaden

7. R. Saraf, New IIniv., Inited Kingdom 